\title{
CURRENT RESEARCH ON CHEMICAL MODIFICATION OF CELLULOSE
}

\author{
G. TESORO \\ Massachusetts Institute of Technology, Cambridge, Mass., USA
}

\begin{abstract}
Research on the chemical modification of cellulosic textiles has been focussed primarily on crosslinking reactions during the late 1950's and early 1960's. During the last decade, emphasis has shifted to the study of modifications which alter the course of the thermal degradation of cellulose, and more specifically, to the study of compounds, reactions and processes which can be used to decrease flammability in cellulosics.

This paper reviews current knowledge on thermal degradation reactions which occur in unmodified cellulose and in cellulose treated with flame retardants as a conceptual framework in which the effectiveness of specific compounds can be interpreted and discussed.

In addition to exhibiting flame retardant effectiveness, compounds used for decreasing the flammability of cellulosics must satisfy a large number of other requirements which can only be defined with reference to the substrate, the specific application contemplated, and the level of flame resistance which is to be attained.

Highlights of current research in this area are presented, including: recent work on flame retardant compounds used in the manufacture of regenerated cellulose fibers; new reagents and processes for modification of $100 \%$ cotton fabrics by finishing; recent approaches to the complex problem of modifying polyester/cotton blend fabrics for flame resistant (self extinguishing) apparel.
\end{abstract}

\section{INTRODUCTION AND BACKGROUND}

Research on chemical modification of cellulose, particularly on fibers and fabrics for textile use, has been an active field of endeavor since about 1925 . Technologists at Tootal, Broadhurst and Lee in England then discovered that urea-formaldehyde condensation products used as thermosetting compositions on fabrics made from cellulosic fibers could yield significant improvements in the dimensional stability of the fabric, and in its ability to recover from deformation. For half a century since, chemists and physicists have investigated the complex interactions of chemical changes in the cellulose molecule, fiber structure, and properties of modified fibers with performance properties of textile products made from them. Scientific and technological goals have been defined, and some have been attained, in a dynamic search for improved processes and products. Meanwhile, the ever-changing demands and needs of society have continued to provide new challenges for the activities of this interdisciplinary technical community which includes organic and polymer chemists, physicists, engineers and textile technologists.

For many years, a dominant segment of research on cellulose textiles' modification has focussed on reactions designed to provide "easy care" or "durable press" properties to fabrics, stimulated by advances in the technology of synthetic fibers, as well as by new insights into correlations of polymer and fiber structure with properties. The results of this creative and rewarding activity have been covered in recent books. ${ }^{1,2}$ Briefly stated, the major accomplishments of the last decade in this area of cellulose research are:

Elucidation of the effect of fiber structure and morphology on reactivity and on mechanical properties of cellulosic fibers (ref. (1) pp. 719-739; pp. 1115-1149).

Definition of the mechanisms of (heterogeneous) cross-linking reactions in cellulose fibers, and on their effects on fiber and fabric properties (ref. (1) pp. 835-875; pp. 1095-1113).

Synthesis, evaluation and development of new chemical systems for cellulose crosslinking (ref. (2) pp. 135-233; 411-415; 417-464).

Utilization of polyester fibers in blends with cellulosics.
Development of new equipment for commercial processing of garments.

Development work on these subjects is continuing, but activity probably reached a peak in the late sixties, in part now displaced by the pressure of other technological objectives in the fiber and textile industries. For the last $5 \mathrm{yr}$, research efforts on chemical modification of cellulose have been devoted principally to the study of compounds, reactions and processes which can decrease fabric flammability. Interest in this problem is not new, but recent legislation in the United States ${ }^{3}$ reflects heightened concern with fire safety, and growing needs for a broad spectrum of flame resistant textile products.

The purpose of this paper is to review briefly the conceptual basis of current research activity on the chemical modification of textile cellulose with flame retardants.

The terminology used in the discussion which follows is summarized in Table 1 . Terms such as these are generally accepted, but most of them represent descriptive definitions of materials' behavior which should always be carefully qualified with reference to specific systems and test configurations.

Table 1. Definition of terms

\begin{tabular}{ll}
\hline Flammability & $\begin{array}{l}\text { Tendency to ignite and propagate } \\
\text { the flame on exposure to elevated } \\
\text { temperature. }\end{array}$ \\
Flame retardant & $\begin{array}{l}\text { Compound or combination of com- } \\
\text { pounds which decrease the flamma- } \\
\text { bility of a substrate to which it is } \\
\text { added. } \\
\text { Does not continue to propagate the } \\
\text { flame when the source of ignition is } \\
\text { removed. (With reference to specific } \\
\text { test configuration and environment.) }\end{array}$ \\
Pelf extinguishing (SE) & $\begin{array}{l}\text { Percent oxygen in the environment } \\
\text { which sustains flaming combusition } \\
\text { in candle-like (downward) burning } \\
\text { under specified test conditions. }\end{array}{ }^{4}$ \\
Oxygen index & $\begin{array}{l}\text { Exhibits decreased flammability } \\
\text { (self extinguishing, and/or high ox- } \\
\text { ygen index). }\end{array}$ \\
Flame resistant (FR)
\end{tabular}




\section{THERMAL DEGRADATION OF CELLULOSE}

Thermal degradation of cellulosic materials proceeds through a complex series of concurrent and consecutive chemical reactions which are schematically illustrated in Fig. $1 .^{5}$ Individual reactions are influenced by the temperature and rate of heating, by the environment (particularly oxygen, water and other reactive or inert gases), and by the composition and physical form (surface area) of the substrate. Heating at moderate temperatures generally favors dehydration and charring reactions, while formation of levoglucosan, an important intermediate in the thermal degradation of cellulose, takes place at higher temperatures. The results shown in Table 2 illustrate the effect of temperature on the relative amounts of "tar" and levoglucosan formed in an experiment on the vacuum pyrolysis of cotton. ${ }^{6}$

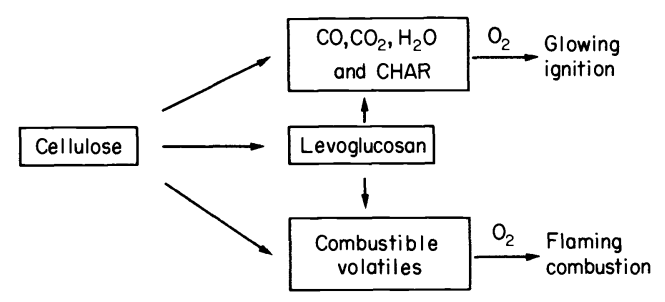

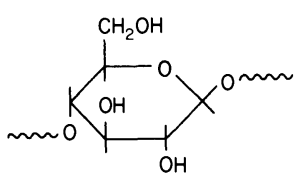

Cellulose (anhydroglucose) unit

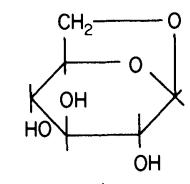

Levoglucosan

I,6 anhydro $\beta \cdot D-$ glucopyranose
Fig. 1. Pyrolysis and combustion of cellulose.

Table 2.6 Maximum yields of tar and levoglucosan from cotton cloth (vacuum pyrolysis) $\%$ yield (w/w dry cotton)

\begin{tabular}{ccc}
\hline Temp $\left({ }^{\circ} \mathrm{C}\right)$ & Tar & Levoglucosan \\
\hline 350 & 63 & 27 \\
420 & 70 & 36 \\
456 & 78 & 44 \\
500 & 74 & 27 \\
\hline
\end{tabular}

The large number of specific reactions and products involved in the thermal degradation of cellulose have been the subject of extensive studies. Mechanisms and Kinetics remain controversial, ${ }^{5}$ but it has been established that the first step in cellulose degradation is the production of levoglucosan ${ }^{7}$ which either decomposes to volatile fragments, or reacts further to produce char as indicated in Fig. 1.

The principal role of acid or acid-forming flame retardants in cellulose is to enhance dehydration and char formation in the condensed phase, suppressing the formation of combustible volatiles in the thermal degradation process. This theory was first postulated by Schuyten et al. about $20 \mathrm{yr} \mathrm{ago}^{10}$ and has been supported by experimental evidence obtained on many cellulosic substrates and flame retardant compounds. Dehydration catalyzed by Lewis Acids can proceed either by a carbonium ion mechanism or by esterification and subsequent decomposition, as shown in reactions (1) and (2) in Fig. 2. Reaction (1) would be expected to proceed rapidly and to be favored by the presence of strong acids, while reaction (2) may proceed more slowly, and even in discreet steps, depending on the stability of the intermediate ester. However, many acids which have similar overall effect on the products of thermal decomposition (phosphoric, sulfuric, sulfamic, boric, etc.), readily form esters.

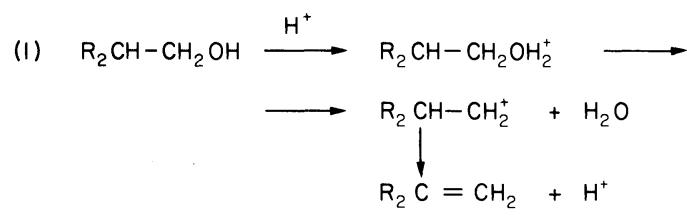

Carbonium ion catalysis

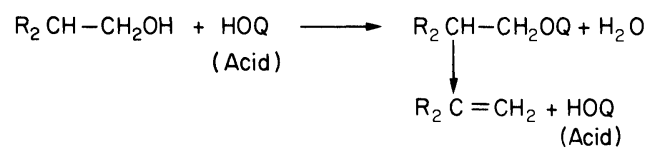

(E.G. $\mathrm{HOQ}=\mathrm{HO} \stackrel{{ }_{\mathrm{O}}^{\mathrm{O}}}{\text { Esterification }}-\mathrm{OH}=$ Phosphorylation)

Fig. 2. Dehydration of cellulose (acid catalyzed).

The mechanism of effectiveness of phosphorus flame retardants has been studied more extensively than for most other compounds, since it has been recognized for some time that phosphorus acids are particularly efficient (ref. (9), pp. 17-19) in reducing the activation energy barrier and decreasing the heat generated in the pyrolysis of cellulose. For example, data from the work of Schuyten et al. ${ }^{10}$ on the dehydration of cellulose are shown in Table 3 for cotton fabric treated with prototype phosphorus flame retardants, diammonium phosphate and tetrakis-hydroxymethyl-phosphonium chloride (THPC), which remain of interest today as components of nondurable and durable flame retardant treatments respectively.

Thermogravimetric analysis of cotton fabrics treated with flame retardants has provided significant evidence for the proposed dehydration mechanism ${ }^{11}$ of flame retardation in cellulose. Although values obtained for the onset of decomposition temperature, and for char yield (percentage residue) in such thermogravimetric studies

Table 3. Dehydration of cellulose ${ }^{10}$

\begin{tabular}{lcc}
\hline Theoretical & $\begin{array}{c}\text { Ratio } \mathrm{C} / \mathrm{H} \\
\text { in residue }\end{array}$ & $\begin{array}{c}\text { Moles } \mathrm{H}_{2} \mathrm{O} \\
\text { lost/glucose }\end{array}$ \\
\hline $\mathrm{C}_{6} \mathrm{H}_{10} \mathrm{O}_{5}-\mathrm{H}_{2} \mathrm{O} \rightarrow \mathrm{C}_{6} \mathrm{H}_{8} \mathrm{O}_{4}$ & 0.75 & 1 \\
$\mathrm{C}_{6} \mathrm{H}_{8} \mathrm{O}_{4}-\mathrm{H}_{2} \mathrm{O} \rightarrow \mathrm{C}_{6} \mathrm{H}_{6} \mathrm{O}_{3}$ & 1.0 & 2 \\
$\mathrm{C}_{6} \mathrm{H}_{6} \mathrm{O}_{3}-\mathrm{H}_{2} \mathrm{O} \rightarrow \mathrm{C}_{6} \mathrm{H}_{4} \mathrm{O}_{2}$ & 1.5 & 3 \\
$\mathrm{C}_{6} \mathrm{H}_{4} \mathrm{O}_{2}-\mathrm{H}_{2} \mathrm{O} \rightarrow \mathrm{C}_{6} \mathrm{H}_{2} \mathrm{O}$ & 2.0 & 4 \\
$\mathrm{C}_{6} \mathrm{H}_{2} \mathrm{O}-\mathrm{H}_{2} \mathrm{O} \rightarrow \mathrm{C}_{6}$ & $\infty$ & 5 \\
${\text { Treated cotton fabrics at } 500^{\circ} \mathrm{C}}_{5}$ & 4.56 & 4.35 \\
$5.8 \%\left(\mathrm{NH}_{4}\right)_{2} \mathrm{HPO}_{4}$ & 2.78 & 3.92 \\
$16 \%$ & & \\
\hline
\end{tabular}


are critically dependent on the specific substrate and on the conditions of the experiment (environment and heating rate) results have been generally consistent with the proposed theories of flame retardant effectiveness. Table 4 summarizes results for cotton fabric treated with varying concentrations of tris-aziridinyl-phosphine oxide (APO). ${ }^{11}$ Some results obtained on phosphorus-containing cotton fabrics in a recent investigation ${ }^{12}$ are shown in Table 5 .

Table 4. Thermogravimetric analysis $\dagger$ of APO-treated cotton fabrics"

\begin{tabular}{cccc}
\hline $\begin{array}{c}\text { \% APO } \\
\text { applied }\end{array}$ & $\begin{array}{c}\text { Temp. at 60\% } \\
\text { residue }\left({ }^{\circ} \mathrm{C}\right)\end{array}$ & $\begin{array}{c}\text { Residue at } \\
400^{\circ} \mathrm{C}(\%)\end{array}$ & $\begin{array}{c}\text { Flammability } \\
\text { (match test) }\end{array}$ \\
\hline 0 & 350 & 13 & $\infty$ \\
3 & 308 & 27 & $\infty$ \\
10 & 291 & 42 & Mod. \\
20 & 286 & 48 & Low \\
\hline
\end{tabular}

$\dagger$ Heating rate $15 \%$ min-in nitrogen atmosphere.

Table 5. Thermogravimetric analysis $\dagger$ of phosphorus-containing cottonfabrics $^{12}$

\begin{tabular}{cccc}
\hline Flame retardant & $\begin{array}{c}\% \text { P in } \\
\text { treated } \\
\text { fabric }\end{array}$ & $\begin{array}{c}\text { Char } \\
\text { area } \\
\mathrm{cm}^{2}\end{array}$ & $\begin{array}{c}\% \\
\text { Residue }\end{array}$ \\
\hline $\mathrm{NH}_{4} \overline{\mathrm{H}}_{2} \mathrm{PO}_{4}$ & 0 & $\infty$ & $(4.3)$ \\
& 1.2 & $\infty$ & 56.3 \\
& 1.7 & 22.1 & 58.6 \\
$\left(\mathrm{HOCH}_{2}\right)_{4} \mathrm{P}^{+} \mathrm{Cl}^{-}$ & 3.3 & 16.5 & - \\
$(\mathrm{THPC})$ & 2.4 & 38.6 & 42.7 \\
\hline
\end{tabular}

†Heating rate $5 \% \mathrm{~min}-$ in vacuum $\left(10^{-3} \mathrm{~mm} \mathrm{Hg}\right)$.

The results of thermoanalytical investigations provide good evidence for the overall enhancement of dehydration reactions by phosphorus compounds, but do not prove whether the mechanism of flame retardant effectiveness entails direct interaction with cellulose (esterification, reaction (2) in Fig. 2), or reaction with levoglucosan and other pyrolysis products formed in the initial stages of thermal degradation. ${ }^{6}$ For phosphorus retardants, evidence for direct interaction with cellulose (phosphorylation) according to the reaction shown schematically below ${ }^{8}$ and corresponding to reaction (2) in Fig. 2 has been obtained by characterizing the chars produced by combustion of treated cotton fabrics.

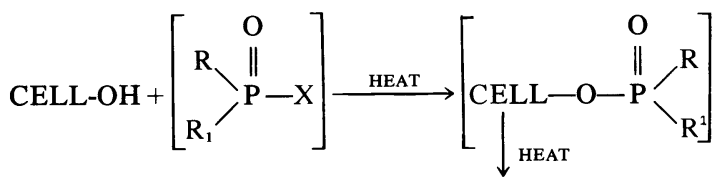

$\mathrm{H}_{2} \mathrm{O}+$ Dehydrated char

Results consistent with this hypothesis have also been reported in a recent study carried out by Differential Scanning Calorimetry (DSC) ${ }^{13}$ on cellulosic fabrics differing in fine structure and modified with flame retardants to an equivalent level of flame resistance (defined by self-extinguishing behavior in a vertical test and by oxygen index). The results obtained indicated significant differences in DSC response between sulfated cellulose and phosphorus-containing cellulose. The differ- ences were interpreted as indications that decomposition of sulfated cellulose may proceed by a carbonium ion mechanism (reaction (1) in Fig. 2) while phosphorylation precedes thermal decomposition in the case of cellulose treated with acid-forming phosphorus compounds.

Chemical modification of cellulose with compounds containing phosphorus remains to date the most important approach to flame resistant cellulosic textiles. For products in which flame resistance must remain unimpaired through multiple laundering, flame retardant phosphorus compounds must be insolubilized in or on fibers, and must be stable to hydrolysis. This clearly entails the design of structures which fulfill many complex requirements of physical properties and reactivity in addition to phosphorus content.

\section{DURABLE FLAME RESISTANCE IN CELLULOSIC TEXTILES}

The requirements for flame resistant cellulosic textiles were outlined by William Henry Perkin in 1913 as follows (Ref. (9), p. 166).

"A process, to be successful, must, in the first place, not damage the feel or durability of the cloth or cause it to go damp as so many chemicals do, and it must not make it dusty. It must not affect the colors or the design woven into the cloth or dyed or printed upon it; nothing (such as arsenic, antimony or lead) of a poisonous nature or in any way deleterious to the skin may be used, and the fireproofing must be permanent, that is to say, it must not be removed even in the case of a garment which may possibly be washed 50 times or more. Furthermore, in order that it may have a wide application, the process must be cheap."

This definition has essentially not been improved upon to this day, while the requirements have been only partially met: clear evidence of the insight of Sir William Perkin, as well as of the complexities of the technical problem.

Table 6 lists the requirements in modern terms, and Table 7 outlines the technological approaches which have been considered for the modification of cellulosic textiles to attain flame resistance.

Flame retardants used for regenerated cellulose fibers are shown in Fig. 3. A viable process has been developed for the use of alkoxyphosphazenes as additives in spinning of regenerated cellulose fibers. ${ }^{14}$ Flame resistant rayon fiber made by this approach is a commercial product. The added flame retardant is "trapped" in the fiber dope, retained through the spinning process and, of course, in use. The structure and physical properties of the flame retardant compound are of critical importance, since the addition of a non-fibrous material in large amounts inevitably decreases fiber tenacity. This general effect is illustrated by a proposed general relationship shown in Fig. $4 .^{15}$

Table 6. Requirements for FR cellulosic textiles

1. Flammability SE in vertical test (e.g. DOC-FF-3-71)

Oxygen index $>28 \%$

Durability under use conditions

\begin{tabular}{|c|c|}
\hline $\begin{array}{l}\text { 2. Performance } \\
\text { properties }\end{array}$ & $\begin{array}{l}\text { Physical properties } \\
\text { Aesthetics } \\
\text { Physiological }\end{array}$ \\
\hline
\end{tabular}

$\begin{array}{ll}\text { 3. Practical } & \text { Processing } \\ \text { considerations } & \text { Environmental } \\ & \text { Economics }\end{array}$


Table 7. Approaches to FR cellulose

1. Incorporation of flame retardant additives in the fiber spinning process (regenerated fibers only)

2. Finishing Deposition of flame retardant compounds Graft copolymerization

In situ polarization

Reaction with cellulose flame retardants hydroxyl groups

(A) Additive in fiber spinning

E.G.

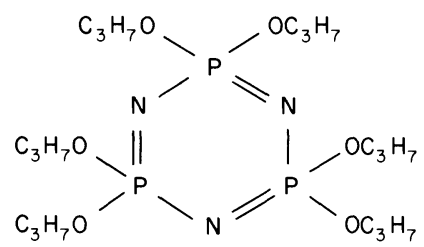

Hexapropoxycyclotriphosphazatriene

(B) Graft copolymerization (Fiber or fabric)<smiles>C=C(C)C(=O)OCCOP(=O)(O)C(=O)OC(F)(F)F</smiles>

Dialkyl phosphatoethyl methacrylate

Fig. 3. Flame retardants for FR rayon.

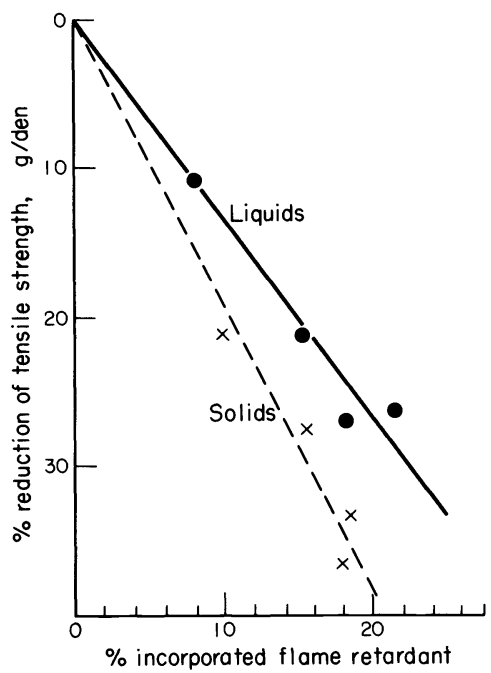

Fig. 4. Effect of flame retardant additives on rayon fiber tenacity.

The development of graft copolymerization processes employing phosphorus-containing monomers on rayon fiber or fabric has received considerable attention, ${ }^{16}$ while fabric finishing processes have not been studied extensively on rayon fabrics. In the case of cotton on the other hand, fabric treatment is the only practical approach to durable flame resistance in fabrics. Insolubilization of phosphorus in finishing is generally attained by reaction of phosphorus compounds with cellulose hydroxyl groups, and formation of stable covalent bonds, or by in situ polymerization of monomer systems which can form three dimensional networks in or on fibers. Phosphoruscontaining compounds which are suitable as components of flame retardant finishes must be reactive enough to be insolubilized under practical conditions in textile mill processing. Flame retardant efficiency of a given finishing system depends on insolubilization yield (phosphorus fixation) as well as on the phosphorus content of the finish, and on the presence and amounts of other elements which may add fuel (e.g. carbon content) or exhibit synergistic interaction with phosphorus in decreasing flammability (e.g. nitrogen).

Numerous organophosphorus compounds have been synthesized and evaluated in flame retardant finishes for cotton fabrics. While few have survived as viable commercial products, analysis of experimental results reported during $20 \mathrm{yr}$ of extensive research suggests some generalizations and working hypotheses for the design of flame retardant compounds which can efficiently catalyze cellulose dehydration and increase char yield in the course of thermal degradation reactions, and consequently decrease the flammability of treated fabrics. A general relationship of phosphorus content to flammability has been established for many diverse phosphorus compounds. As a first approximation, treated cotton fabrics become self extinguishing in vertical flammability tests, and exhibit an oxygen index of 27-29 at phosphorus contents of about $2.0-4.0 \%$, depending on fabric construction and geometry. In the presence of some nitrogen compounds, the minimum phosphorus content required for self extinguishing behavior is significantly lower, indicating synergistic interaction of phosphorus and nitrogen in inhibiting formation of flammable decomposition products during thermal degradation of the cellulose (ref. (9), p. 21; (17), (18)). This effect has been attributed to enhancement of phosphorylation by phosphoramides formed at elevated temperature in the presence of nitrogeneous bases. ${ }^{8,19}$ An example of the increased flame retardant effectiveness of phosphorus in the presence of a nitrogenous base is shown in Fig. 5, a plot of oxygen index vs. diammonium phosphate content for cotton fabric with and without prior treatment with $10 \%$ trimethylol melamine $(5.1 \% \mathrm{~N}$-Ref. (18)). The concept of phosphorus/nitrogen synergism has been valuable in the development of commercially useful finishes, which must combine flame retardant efficiency with high yields of

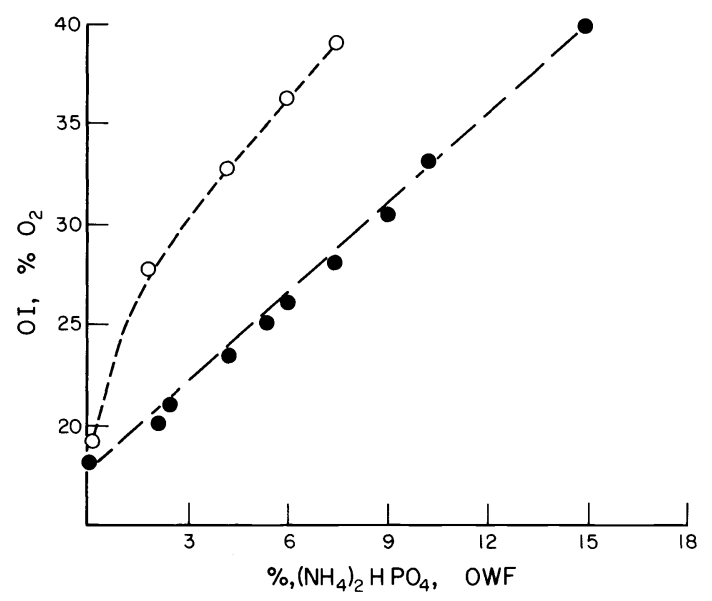

Cotton fabric treated with diammonium phosphate

OPretreated with trimethylol melamine (10\%)

- No pretreatment

Fig. 5. Oxygen index of cotton fabric treated with phosphorus and nitrogen compounds. 
insolubilization, acceptable processing conditions, good fabric properties and reasonable cost.

Systems currently used commercially in the U.S. for flame retardant finishing of $100 \%$ cotton fabrics are shown in Table 8: High concentrations of applied finish are used, with insolubilization yields ranging from about $60-80 \%$. Fabric properties are considered acceptable, but barely, and finishing costs are high. More efficient compounds are needed to decrease the weight gain required in treated fabrics, minimize side effects of the finish on fabric properties and decrease cost. Promising results have been obtained in recent research work aimed at the development of more efficient compounds. In part, this work has been based on hypotheses postulated regarding the structure of efficient phosphorus flame retardants. These should be:

1. Small molecules, capable of penetrating cotton fibers rapidly from aqueous solution;

2. Reactive compounds, which form stable covalent bonds with cellulose hydroxyl groups and do not polymerize on fiber surfaces;

3. Compounds of high phosphorus and low carbon content, which do not themselves form combustible volatile fragments and would not add significant amounts of fuel in the thermal degradation process;

4. Compounds or combinations of compounds which either contain P-N bonds, or can form P-N bonds on heating, for enhanced phosphorylation of cellulose in the initial stages of thermal degradation.

Table 9 summarizes some results obtained in recent investigations with experimental finishes. These demonstrate that self-extinguishing behavior can be obtained in cotton fabrics at moderate weight gains with flame retardants specifically designed for maximum effectiveness on the basis of the best available conceptual knowledge and hypotheses. Commercial development of finishes based on these and other experimental reagents is one of the challenges facing chemists and technologists in this field.

Flammability and flame resistance in polyester/cellulose blends constitute another important technical challenge. Elucidation of the mechanism of thermal degradation in this two-component substrate, approaches to inhibiting combustion of the complex degradation products formed, and development of chemical systems which can impart flame resistance to polyester/cellulose blends fabrics, present formidable problems. Research on these problems began in 1967-68 and definition of approaches was first proposed in $1969 .^{18}$ Since that time, it has been clearly established that flame retardant systems that are effective on $100 \%$ cotton do not necessarily decrease flammability in blends-at least not

Table 8. Commercial chemicals for flame retardant finishing of cotton fabrics

\begin{tabular}{|c|c|c|c|c|c|c|}
\hline Ref. & $\begin{array}{l}\text { Organophosphorus } \\
\text { compound }\end{array}$ & $\begin{array}{l}\text { Coreactant(s) } \\
\text { required }\end{array}$ & Insolubilization & Applied & $\begin{array}{l}\text { nish } \\
\text { Insolu- } \\
\text { bilized }\end{array}$ & $\begin{array}{l}\% \mathrm{P} \text { in } \\
\text { finished } \\
\text { fabric } \dagger\end{array}$ \\
\hline (20) & 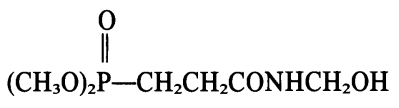 & & $\begin{array}{l}\text { Reaction with } \\
\text { cellulose } \mathrm{OH}\end{array}$ & $30-40$ & $20-30$ & $2-3$ \\
\hline $\begin{array}{l}\text { (9) } \\
\text { pp.189-208 }\end{array}$ & $\begin{array}{c}{\left[\left(\mathrm{HOCH}_{2}\right)_{4} \mathrm{P}\right]+\mathrm{X}^{-}} \\
\mathrm{X}=\mathrm{Cl}, \mathrm{OH} \\
\text { etc. }\end{array}$ & $\begin{array}{c}\mathrm{NH}_{3}, \\
\mathrm{NH}_{2} \mathrm{CONH} \\
\text { etc. }\end{array}$ & $\begin{array}{l}\text { In situ polymerization } \\
\text { with coreactant } \\
\text { (polycondensation) }\end{array}$ & $30-40$ & $25-35$ & $3-5$ \\
\hline (21) & {$\left[-\mathrm{O}-\stackrel{\mathrm{O}}{\mathrm{P}}-\mathrm{OCH}_{2} \mathrm{CH}_{2}-\right]_{\mathrm{n}}$} & $\mathrm{CH}_{2}=\mathrm{CHCONHCH}_{2} \mathrm{OH}$ & $\begin{array}{l}\text { In situ } \\
\text { polymerization } \\
\text { (free radical) }\end{array}$ & $25-35$ & $20-30$ & $2-4$ \\
\hline
\end{tabular}

$\nmid$ Required for SE behavior in vertical flammability tests (depending on specific fabric).

Table 9. Experimental chemicals for flame retardant finishing of cotton fabrics

\begin{tabular}{|c|c|c|c|c|c|}
\hline Ref. & $\begin{array}{l}\text { Organophosphorus } \\
\text { compound }(\% \mathrm{P})\end{array}$ & $\begin{array}{l}\text { Coreactant(s) } \\
\text { required }\end{array}$ & $\begin{array}{l}\text { Insolubilization } \\
\text { mechanism }\end{array}$ & $\begin{array}{c}\% \text { Finish } \\
\text { Insolu- } \\
\text { bilized }\end{array}$ & $\begin{array}{l}\% \mathrm{P} \text { in } \\
\text { finished } \\
\text { fabric } \dagger\end{array}$ \\
\hline (22) & $\begin{array}{l}\mathrm{P}\left(\mathrm{NH}_{2}\right)_{3} \\
{ }_{\mathrm{O}} \\
\end{array}$ & $\begin{array}{c}\mathrm{NH}_{4} \mathrm{SO}_{3} \mathrm{NH}_{2} \\
+ \\
\text { Bis-methoxymethyl } \\
\text { uron }\end{array}$ & $\begin{array}{l}\text { Reaction } \\
\text { with } \\
\text { cellulose } \\
\text { OH }\end{array}$ & $15-20$ & $\begin{array}{l}2.0-2.2 \\
(+2 \% \mathrm{~S})\end{array}$ \\
\hline (23) & $\underset{\mathrm{O}}{\mathrm{ClCH}_{2} \mathrm{P}}{ }_{(17.2)}$ & - & $\begin{array}{l}\text { Reaction } \\
\text { with } \\
\text { cellulose } \\
\text { OH }\end{array}$ & $8-16$ & $2.0-3.1$ \\
\hline (24) & $\begin{array}{c}\mathrm{CH}_{3} \mathrm{P}\left(\mathrm{NH}_{2}\right)_{2} \\
\| \\
\mathrm{O} \\
(33.0)\end{array}$ & - & $\begin{array}{l}\text { Reaction } \\
\text { with } \\
\text { cellulose } \\
\text { OH }\end{array}$ & $7-14$ & $1.8-3.6$ \\
\hline
\end{tabular}

†Required for SE behavior in vertical flammability tests (depending on specific fabric). 
Table 10. Approaches to flame resistant polyester/cellulose blends

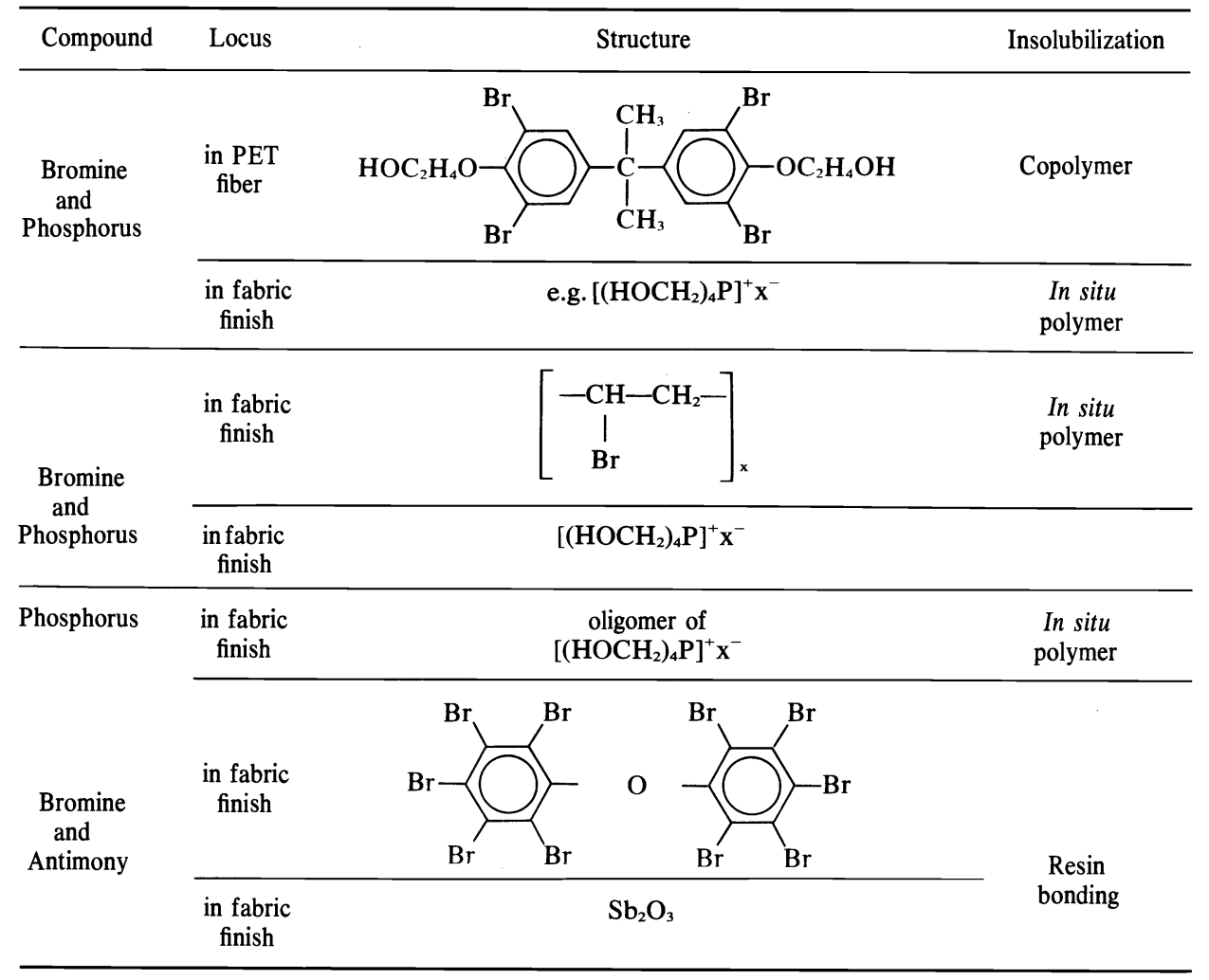

in terms of self-extinguishing behavior in vertical tests. Furthermore, finishes applied to blends from aqueous solution tend to penetrate cotton fibers preferentially, and the concentration of reactive compounds in the cotton becomes exceedingly high. The concentration of hydroxyl groups in the substrate is lower in the case of blends (in proportion to the polyester content), and the yield of insolubilization reactions involving $\mathrm{OH}$ groups is low. Distribution and adhesion of polymers formed in situ have a profound effect on fabric properties and finish durability.

Research activity on durably flame retardant finishes for polyester/cotton blends has resulted in considerable progress, ${ }^{25}$ and some promising results are emerging, even though commercially finished blend fabrics containing $50 \%$ or more polyester are not available. A review of this problem is beyond the scope of this paper, and only salient facts will be mentioned briefly.

Approaches to current finishing developments on blends are briefly summarized in Table 10. Flame retardancy is obtained through the presence of phosphorus, or bromine, or combinations of these elements. On a short range basis, research is focused on the modification of the cellulose component in blends of cotton with "conventional" polyester, or with a brominecontaining polyester (Dacron $900 \mathrm{~F}^{(\mathrm{R})}$, a copolymer in which part of the ethylene glycol is replaced by the glycol obtained from addition of ethylene oxide to tetrabromobis phenol A) now available from the Dupont Company in semi-commercial quantities. When "conventional" polyester fiber in polyester/cotton blend fabrics is replaced by this copolymer fiber (which contains approximately $6 \%$ bromine), or by an equivalent modified polyester fiber, lower amounts of flame retardant finish are required to meet a given flammability test and undesirable effects on fabric properties are reduced.
The synthesis and evaluation of new flame retardant phosphorus compounds which are specifically designed to inhibit combustion of cellulose in the presence of polyester is an important long-range objective. Work in progress is aimed at compounds which would be suitable as additives in regenerated cellulose fibers to be used in blends, as well as on reactive compounds designed as components of flame retardant finishes for polyester/cotton fabrics.

In summary, continuing research on chemical modification of cellulose has brought within reach the goal of self-extinguishing $100 \%$ cotton fabrics in which aesthetics and performance are adequate for the U.S. consumer market. Further work is needed to attain comparable results on polyester/cellulose blends, and this problem is far more complex. It is perhaps the major research challenge of the future in the field of chemical modification of cellulose textile fibers.

\section{REFERENCE}

${ }^{1}$ N. M. Bikales and L. Segal (Eds), Cellulose and Cellulose Derivatives. John Wiley, New York (1971). (Volume V, parts IV and $\mathrm{V}$ in series on High Polymers).

${ }^{2}$ H. Mark, N. S. Wooding and S. M. Atlas (Eds), Chemical after Treatment of Textiles. Wiley-Interscience, New York (1971).

${ }^{3 a}$ Flammable Fabrics Act (December, 1967). ${ }^{b}$ Consumer Products Safety Act (October, 1972). ${ }^{c}$ Federal Fire Prevention and Control Act (October, 1974).

${ }^{4 a}$ C. P. Fenimore and F. J. Martin, Modern Plastics 44, 141 (1966); ${ }^{b}$ C. P. Fenimore and G. W. Jones, Combustion and

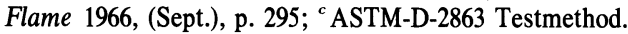

${ }^{5} \mathrm{~F}$. Shafizadeh, Advances in Carbohydrate Chemistry, 23, 419 (1968).

${ }^{6}$ G. A. Byrne, D. Gardiner and F. H. Holmes, J. Appl. Chem. 16, 81 (1966).

${ }^{7}$ S. L. Madorsky, Thermal Degradation of Organic Polymers, Wiley-Interscience, New York (1964).

${ }^{8 a}$ M. J. Drews and R. H. Barker, J. Fire Flammability 5, 116 
(1974); ${ }^{b}$ M. J. Drews, K. Yeh and R. H. Barker, Textilveredlung 8, 180 (1973).

${ }^{9} \mathrm{~J}$. W. Lyons, The Chemistry and Uses of Fire Retardants. Wiley-Interscience, New York (1970).

${ }^{10}$ H. A. Schuyten, J. W. Weaver and D. J. Reid, Ind. Eng. Chem. 47, 1433 (1955).

${ }^{11}$ R. M. Perkins, G. L. Drake and W. A. Reeves, J. Appl. Pol. Sci. 10, 1041 (1966).

${ }^{12}$ K. Katsuura and N. Inagaki, Tex. Res. J. 45, 103 (1975).

${ }^{13}$ A. Basch and M. Lewin, Tex. Res. J. 45, 246 (1975).

${ }^{14 a}$ L. E. Godfrey and J. W. Schappel, Ind. Eng. Chem. Prod. Res. Dev. 9(4), 426 (1970); ${ }^{b}$ L. E. Godfrey, Tex. Res. J. 40, 116(1970).

${ }^{15} \mathrm{H}$. Krässig, New and future developments in man-made cellulose fiber industry. 3rd International Dissolving Pulps Conference, Atlanta, Georgia, October 24-26, 1973.

${ }^{16 a} \mathrm{~W}$. J. Brickman and F. W. Faessinger, Textile Chemist Colorist 5, 94 (1973); ${ }^{b}$ H. A. Krässig, Papier 24, 926 (1970).

${ }^{17}$ G. Tesoro, S. B. Sello and J. J. Willard, Tex. Res. J. 39, 180 (1969).
${ }^{18} \mathrm{G}$. Tesoro and C. Meiser, Tex. Res. J. 40, 430 (1970).

${ }^{19 a}$ J. Hendrix, J. E. Bostic, E. S. Olson and R. H. Barker, J. Appl. Polym. Sci. 14, 1701 (1970); ${ }^{b}$ J. Hendrix, G. L. Drake and R. H. Barker, J. Appl. Polym. Sci. 16, 41 (1972).

${ }^{20}$ R. Aenishanshlin, C. Guth, P. Hoffman, A. Maeder and H. Nachbur, Tex. Res. J. 39, 375 (1969).

${ }^{21}$ B. J. Eisenberg and E. D. Weil, Textile Chemist and Colorist 6, 180 (1974)

${ }^{22}$ P. Isaacs, M. Lewin, S. B. Sello and K. Stevens, Tex. Res. J. 44, 700 (1974).

${ }^{23} \mathrm{G}$. Tesoro, W. Olds and R. Babb, Textile Chemist and Colorist 6(7), 148 (1974).

${ }^{24}$ G. Tesoro, E. I. Valko and W. Olds, Paper presented at the Second International Conference on Flammability and Flame Retardants, Montreal, Canada (May 22-23, 1975).

${ }^{25 a}$ G. Tesoro, Report to the National Bureau of Standards NTIS, COM-73-11265 (1973); ${ }^{b} \mathrm{G}$. Tesoro, Textile Chem. Colorist 5, 235 (1973). 